\title{
Damage functions for climate-related hazards: unification and uncertainty analysis
}

\author{
Boris F. Prahl ${ }^{1}$, Diego Rybski ${ }^{1}$, Markus Boettle ${ }^{1}$, and Jürgen P. Kropp ${ }^{1,2}$ \\ ${ }^{1}$ Potsdam Institute for Climate Impact Research (PIK), Potsdam, Germany \\ ${ }^{2}$ Department of Earth and Environmental Sciences, University of Potsdam, Potsdam, Germany \\ Correspondence to: Boris F. Prahl (corr@prahl.net)
}

Received: 25 September 2015 - Published in Nat. Hazards Earth Syst. Sci. Discuss.: 12 November 2015

Revised: 9 May 2016 - Accepted: 12 May 2016 - Published: 25 May 2016

\begin{abstract}
Most climate change impacts manifest in the form of natural hazards. Damage assessment typically relies on damage functions that translate the magnitude of extreme events to a quantifiable damage. In practice, the availability of damage functions is limited due to a lack of data sources and a lack of understanding of damage processes. The study of the characteristics of damage functions for different hazards could strengthen the theoretical foundation of damage functions and support their development and validation. Accordingly, we investigate analogies of damage functions for coastal flooding and for wind storms and identify a unified approach. This approach has general applicability for granular portfolios and may also be applied, for example, to heatrelated mortality. Moreover, the unification enables the transfer of methodology between hazards and a consistent treatment of uncertainty. This is demonstrated by a sensitivity analysis on the basis of two simple case studies (for coastal flood and storm damage). The analysis reveals the relevance of the various uncertainty sources at varying hazard magnitude and on both the microscale and the macroscale level. Main findings are the dominance of uncertainty from the hazard magnitude and the persistent behaviour of intrinsic uncertainties on both scale levels. Our results shed light on the general role of uncertainties and provide useful insight for the application of the unified approach.
\end{abstract}

\section{Introduction}

As climate extremes, natural hazards are an inherent part of the climate system. There is increasing evidence that a changing climate leads to changes in hazard characteristics and can even result in unprecedented extreme weather and climate events (IPCC, 2012). For instance, sea level rise aggravates the intensity of coastal floods such that expected damage increases more rapidly than mean sea level (Boettle et al., 2016).

For a risk assessment of natural hazards, damage functions are employed to translate the magnitude of extreme events to a quantifiable damage. Often the focus is on the modelling of the hazard, while the damage assessment receives less attention (Merz et al., 2010).

Accordingly, the availability of damage functions is very limited. On the one hand, empirical damage functions may not be inferable due to a lack of observations for certain impacts or sites. On the other hand, the correlations between loss and the explanatory variable(s) might be weak and loss estimates could become unreliable due to the high level of uncertainty. This results in the need for a comprehensive damage assessment in order to enable the quantification and comparison of the impacts from different natural hazards and their interactions (Kreibich et al., 2014).

For this purpose, the work at hand provides an investigation into the common aspects of damage functions for different hazards. It considers similarities in damage functions and exposure for coastal flooding (as applied by Hinkel et al., 2014) and windstorms (Heneka and Ruck, 2008). A general derivation of the damage functions reveals that these constitute two facets of a more general approach which we refer to as a unified damage function.

Moving towards a multi-risk assessment, it is shown how this approach can be extended to heat-related mortality. This is of particular concern since heat-related fatalities currently comprise over $90 \%$ of total natural hazard fatalities in $\mathrm{Eu}-$ 

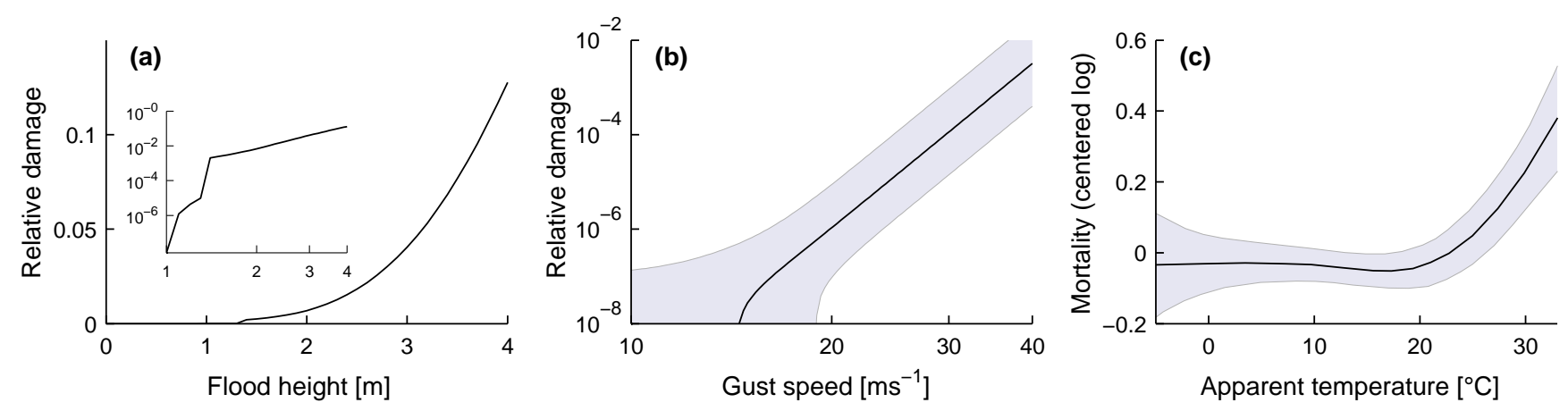

Figure 1. (a) Relative flood damage function obtained for the case study of Kalundborg (Boettle et al., 2011), with a log-log inset. (b) Relative storm-damage function for a German district (Prahl et al., 2012). (c) Damage function for the city of Bologna, relating mortality increase to apparent temperatures (data extracted from Stafoggia et al., 2006). The shaded areas in (b) and (c) represent uncertainty bands.

rope and are also a major issue for developing countries (Golnaraghi et al., 2014; Munich Re, 2013).

The unified damage function also provides a platform for the discussion of potential uncertainties. Embedding the damage function in a probabilistic framework, this study investigates the relevance of different uncertainty sources for damage estimation. Excluding considerations about the stochastic nature of extreme events, we consider uncertainties in the damage function subject to a hypothetical hazard magnitude. A variance-based sensitivity analysis (VBSA) (Saltelli et al., 2008) is employed to quantify the influence of uncertainties at different hazard magnitudes. Furthermore, the analysis compares the relevance of uncertainties on the microscale and the aggregated portfolio levels. As a result, the work at hand provides indications for considering relevant uncertainties in damage assessments.

In Sect. 2, we begin by deriving the basis of the unified damage function in the context of coastal flooding and windstorms and extend the concept to heat-related mortality. The role of different uncertainties is discussed in Sect. 3, where we also derive the probabilistic framework for the unified damage function. Two case studies are parameterized in Sect. 4 to serve as the basis for the sensitivity analysis conducted in Sect. 5. We conclude with a discussion of our key results in Sect. 6.

\section{Unified damage function}

Damage functions are an important tool for an impact assessment of climate-related hazards. For example, Fig. 1 shows three damage functions that relate to the hazards of coastal flooding, wind storms, and excessive heat. It is the goal of this section to determine a unified damage function that has applicability in each of these fields. For this purpose, the analogies between two existing damage functions for coastal floods and windstorms are analysed and an extension to heatrelated mortality is proposed.
Henceforth, we rely on the following definitions. A damage function is defined as the mathematical relation between the magnitude of a (natural) hazard and the average damage caused on a specific item (building, person, etc.) or portfolio of items. The emphasis is on direct monetary damage, but the findings can be generalized to any measurable quantity.

In this context, the microscale level relates to a single item. In contrast, the macroscale level refers to a portfolio of independent items with similar properties (e.g. residential buildings). With this definition, we go beyond similar definitions that define the macro domain solely via the spatial extent (e.g. Merz et al., 2010). In the regional context, the macroscale damage function may refer to a city or otherwise spatially delineated portfolio.

Damage can be expressed in absolute or relative terms (Merz et al., 2010). In order to facilitate comparison between different hazards, we consistently employ relative figures for both micro- and macroscale damage.

\subsection{Coastal floods - explicit threshold representation}

In the following, we give account of a damage function that has been frequently applied for the assessment of coastal flooding (e.g. Boettle et al., 2011; Hinkel et al., 2014).

We begin by defining a microscale damage function $g$, which relates the relative damage $r$ of an item $i$ to the hazard magnitude $x$ :

$r_{i}=g\left(x-\lambda_{i}\right)$

The damage is conditional on the exceedance of the itemspecific hazard threshold $\lambda_{i}$. In other words, a single item will suffer damage only if its hazard threshold is exceeded.

The hazard magnitude may be represented by a more or less complex indicator. Frequently the most basic indicator, maximum flood height, is chosen (Hallegatte et al., 2013; Hinkel et al., 2014). Neglecting ancillary damaging effects, such as floating debris, the damage to an individual building is dominated by the inundation. Accordingly, the hazard 

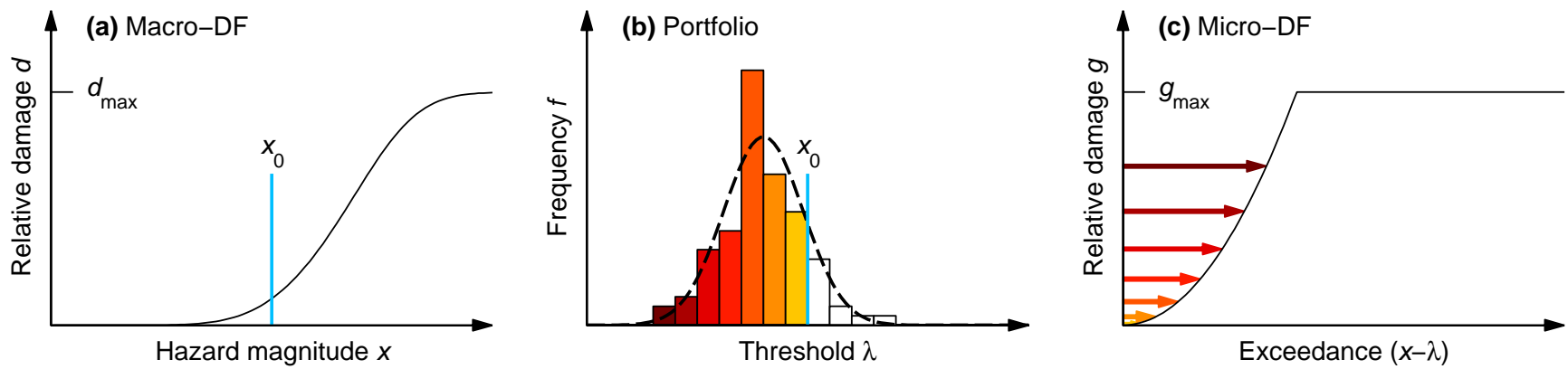

Figure 2. Schematically, (a) shows a macroscale damage function based on a building portfolio with a distribution of hazard thresholds as shown in (b), where coloured bars indicate portfolio segments affected at hazard magnitude $x_{0}$. (c) shows the applied microscale damage function. Accordingly, the coloured arrows indicate the damage inflicted on the respective portfolio segments at $x_{0}$.

threshold is identified as the elevation of the building site and the threshold exceedance as the inundation level.

The microscale damage function has a lower bound of 0 for $x<\lambda_{i}$ and increases monotonically to its upper bound $g_{\max }$ for $x \geq \lambda_{i}$. Considering relative damages, the upper bound is less than or equal to 1 and represents the potential maximum damage. In general, $g$ can exhibit jumps and may hence not be differentiable.

For a macroscale damage assessment, e.g. for a coastal city, it is assumed that all items in the portfolio are exposed to the same hazard magnitude. Local fluctuations (e.g. caused by obstruction or varying distance to coast) are considered as a source of uncertainty in Sect. 3. For now, the fraction of affected items $c$ within a portfolio of $n$ items is given by the number of items for which $x$ reaches or exceeds $\lambda_{i}$. Explicitly,

$c_{\text {expl }}(x)=\frac{1}{n} \sum_{i=1}^{n} \mathcal{H}\left(x-\lambda_{i}\right)$,

where $\mathcal{H}$ denotes the Heaviside step function, defined as

$\mathcal{H}(z)= \begin{cases}0, & \text { for } z<0 \\ 1, & \text { for } z \geq 0\end{cases}$

The damage ratio for the portfolio (relative damage) is given by the average damage of the individual items:

$$
\begin{aligned}
d_{\operatorname{expl}}(x) & =\frac{1}{n} \sum_{i=1}^{n} g\left(x-\lambda_{i}\right) \\
& =\frac{1}{n} \sum_{i=1}^{n} r_{i} .
\end{aligned}
$$

While the above equation assumes equal monetary value for each item, generalization is simple. Different item values can be incorporated by weighting the sum with a normalized asset value $v_{i}$ (i.e. rescaled such that the average equals 1 ).

In order to emphasize the similarity to the storm-damage function described in the following section, we define a discrete frequency distribution $f\left(\lambda_{j}\right)$ for the portfolio and rewrite Eq. (4) as

$d_{\operatorname{expl}}(x)=\sum_{j} f\left(\lambda_{j}\right) g\left(x-\lambda_{j}\right)$

where the sum runs over all discretized threshold values $\lambda_{j}$.

The relationship between macroscale damage, portfolio composition, and microscale damage function is shown schematically in Fig. 2. Given a hypothetical hazard magnitude of $x_{0}$, all colour-coded portfolio segments will be affected since $x_{0}$ exceeds their threshold. Accordingly, the coloured arrows in Fig. 2c indicate the damage suffered by each portfolio segment. The sum of these damages amount to the macroscale damage level seen in Fig. 2a.

The key characteristic of this approach is the consideration of a granular portfolio of buildings, each with an observable hazard threshold. The approach is reliant on the availability of building-specific information and prior knowledge on the microscale damage function and hence represents a bottomup approach.

\subsection{Wind storms - implicit threshold representation}

In this section we give account of a storm-damage function developed by Heneka and Ruck (2008), which is then set into contrast with the previously discussed coastal flood damage function.

Storm-damage functions are typically calibrated to insurance data. The data comprise the fraction of affected buildings (claim ratio) and the damage ratio for a defined region (Prahl et al., 2012).

It can be assumed that buildings have a specific resistance to wind (i.e. a threshold wind speed) that depends on their characteristics (Walker, 2011). However, the detailed building characteristics are usually not known and there is no simple proxy for the hazard threshold. In consequence, the hazard threshold must be defined probabilistically, as follows.

In analogy to the coastal flood example, let $\lambda_{i}$ denote the hazard threshold of an individual item. From a probabilistic point of view, $\lambda_{i}$ constitutes an independent realization of 
a random variable $\Lambda$, whose probability density distribution is given by $f_{\Lambda}(\lambda)$.

For a given portfolio, $P(\Lambda \leq x)$ represents the expected value of the share of items whose hazard threshold has been attained or exceeded at a given $x$. Hence, the claim ratio is defined by the distribution of hazard thresholds:

$$
\begin{aligned}
c_{\mathrm{impl}}(x) & =P(\Lambda \leq x) \\
& =\int_{0}^{x} f_{\Lambda}(\lambda) \mathrm{d} \lambda .
\end{aligned}
$$

Having identified the distribution of hazard thresholds, the macroscale damage ratio is given by the convolution of the probability density of the hazard threshold and the microscale damage function $g(x-\lambda)$ :

$$
\begin{aligned}
d_{\mathrm{impl}}(x) & =\left(f_{\Lambda} * g\right)(x) \\
& =\int_{0}^{x} f_{\Lambda}(\lambda) g(x-\lambda) \mathrm{d} \lambda .
\end{aligned}
$$

In other words, the potential damage at any hazard threshold $\lambda$ is weighted with the probability density of $\lambda$. Via integration, the macroscale damage comprises all the contributions from hazard thresholds below the hazard magnitude $x$.

As in the previous case of coastal flooding, the damage function considers a granular portfolio of exposed buildings. The key difference is that in the case of wind storms a direct observation of the hazard threshold is not feasible. Instead, an implicit description of the portfolio is given by the distribution of hazard thresholds. In order to obtain this distribution, the damage function is calibrated against macroscale damage data in a top-down approach.

Simple inspection shows that Eq. (7) for wind storm is the continuous analogue to Eq. (5) for coastal flooding. Consequently, both approaches - bottom-up in the case of coastal floods and top-down for wind storms - can be understood as different facets of a unified damage function.

\subsection{Extension to heat-related mortality}

Formally, the mathematical relationships derived in the previous sections also hold for other natural hazards such as heat-related mortality.

In general terms, the mortality rate is a measure of fatalities in a given population over a certain period of time. While it is not always possible to attribute fatalities to distinct causes, the effect of excess mortality due to the impact of heat waves has been widely studied (e.g. Gasparrini et al., 2015; Leone et al., 2013). Typically, excess mortality describes the increase of daily mortality in relation to a temperature indicator. An example for excess mortality for the city of Bologna is given in Fig. 1c. As can be seen, the expected mortality starts to increase just above $20^{\circ} \mathrm{C}$ of apparent temperature
(Stafoggia et al., 2006). In absolute terms, the increase in mortality can be defined as the daily number of heat-related fatalities divided by the total population.

Although it is a delicate issue to discuss human mortality in a technical language, we believe that it allows for an intuitive and meaningful application of the unified damage function. First, decease is expressed via a Heaviside step function, where 0 and 1 denote life and death respectively. The step function takes the part of the microscale damage function $g$ in the unified damage function. Second, the hazard threshold relates to the maximum heat-wave intensity (e.g. apparent temperature) tolerated by an individual. While this threshold is generally not known and may also fluctuate over time, a statistical description of the distribution of heat-wave thresholds within the population would be feasible.

Extending the regional focus, Leone et al. (2013) and others have shown an influence of local climatic conditions as well as socio-demographic and economic characteristics on the shape of the damage function. However, a comprehensive decomposition of the hazard threshold is yet to be found.

Caution should be taken when considering the uncertainty of the hazard threshold. In contrast to the cases of coastal flood and storm damages, where building portfolios change only gradually, human heat tolerance is subject to continuous biophysical, behavioural, and environmental changes. Hence, a path dependence of the threshold exceedance is expected for ongoing heat waves.

\section{Uncertainty}

While the stochastic occurrence of hazardous events has been subject to ample research, the origin and propagation of uncertainty within the damage function has received less attention. Often, a rough understanding of sensitivity is obtained from estimating alternative scenarios (e.g. Hallegatte et al., 2013; Hinkel et al., 2014). Other studies focus on an empirical description of uncertainty (e.g. Heneka and Ruck, 2008; Merz et al., 2004) but do not provide a comprehensive analysis of potential sources.

To enable a comprehensive sensitivity analysis of uncertainty from different sources, the unified damage function is cast into a probabilistic framework. We begin by defining a taxonomy of uncertainty sources that are relevant in our context.

\subsection{Brief taxonomy of uncertainty sources}

Uncertainties arise at each step along the causal chain, from the modelling or observation of the hazard through the estimation of micro- and macroscale damage to the validation against reported losses. We focus on the propagation of uncertainties within the damage function, linking the microscale with the macroscale behaviour. For this reason, model and parametric uncertainty are excluded. Model un- 
certainty would arise from selecting an inadequate damage function that deviates from the actual hazard-damage relation. Parametric uncertainty relates to incomplete knowledge about the model parameters (but not the explanatory variables).

It is common to categorize uncertainties into those that are due to statistical variability (aleatory) and those that are due to incomplete knowledge (epistemic) (Merz and Thieken, 2009). While model and parametric uncertainty belong to the latter category, the attribution is not clear-cut for uncertainties in explanatory variables. In principle, all aleatory uncertainty could be addressed as epistemic by raising the level of detail and modelling all minute sub-scale processes. Hence, Bedford and Cooke (2001) state that "the categorization into aleatory and epistemic uncertainties is for the purposes of a particular model".

In order to maintain an intermediate level of detail, the considered uncertainties are classified as aleatory, i.e. statistically tractable. Having excluded model and parametric uncertainty, the remaining sources of uncertainty can be identified from the mathematical description of the damage function. For this purpose, Eq. (4) is cast into its most general form, including a variable asset weight $v_{i}$ and allowing for a local hazard magnitude $\widetilde{x}_{i}$ to fluctuate around $x$ :

$d_{\operatorname{expl}}(x)=\frac{1}{n} \sum_{i=1}^{n} v_{i} \underbrace{g(\overbrace{\tilde{x}_{i}}^{e_{i}} \overline{\lambda_{i}}}_{r_{i}})$.

On the right-hand side of Eq. (8), the asset weight $v_{i}$, the relative damage $r_{i}$, and the exceedance $e_{i}$ are identified as potential sources of uncertainty. These are intrinsic uncertainty sources as they manifest within the damage function. On the left-hand side, the hazard magnitude represents an extrinsic source of uncertainty for the damage function. If observations of macroscale damage were available for the calibration or validation, these would represent an additional source of extrinsic uncertainty.

The sources of uncertainty are summarized in Fig. 3 and each source is briefly described in the following.

a. The asset values of affected items can vary significantly (e.g. different house prices). The attribution of values to location is feasible only on a detailed case study level, while large-scale assessment typically relies on by-proxy estimation of average asset value (e.g. Hallegatte et al., 2013; Hinkel et al., 2014). Especially in the latter case, unknown asset values pose a significant source of uncertainty.

b. Even if structures of similar type are equally affected (i.e. at the same threshold exceedance) their damage can differ considerably. The underlying damaging processes are not well understood and are dependent on construction types and employed materials. The resulting uncertainty could in principle be reduced by modelling all

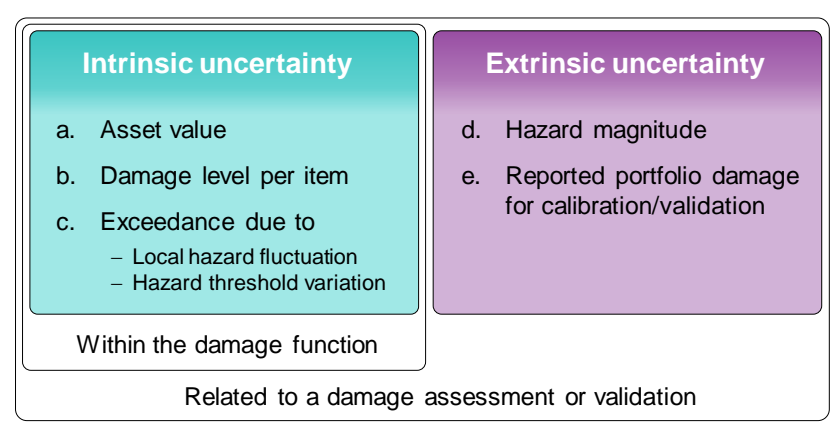

Figure 3. Classification of the sources of uncertainty into intrinsic and extrinsic.

physical processes involved. However, data limitations usually permit no more than a stratification to a few predefined asset classes (Hammond et al., 2015).

c. The threshold exceedance for an item is subject to uncertainty in the hazard threshold $\left(\lambda_{i}\right)$ and fluctuations of the local hazard magnitude $\left(\widetilde{x}_{i}\right)$. The hazard threshold may either be not directly observable (e.g. for storm damage) or be affected by measurement error (e.g. using elevation models for flood damage assessment). Similarly, the local hazard magnitude is affected by observational or modelling error.

d. On the macroscale level, the hazard magnitude is typically described by a single indicator (e.g. the maximum flood level or gust speed). For all practical purposes, this indicator is subject to uncertainty, stemming either from imprecise measurement, uncertain model output, or confidence levels estimated from extreme value statistics (Coles and Tawn, 2005). Prahl et al. (2012) highlight the relevance of this uncertainty by indicating that variability of reported storm losses could be largely due to uncertainty in wind measurements.

e. For purposes of calibration and validation, model estimates are often put into comparison with reported figures of damage or economic loss. Like any observation, these figures are subject to uncertainty. For example, reported figures may be affected by gradual damage accumulation masking the effect of individual hazard occurrences, by incentives for insurance holders (e.g. deductibles), and by wealth levels that affect the construction quality and the likelihood of purchasing insurance.

\subsection{Probabilistic description of uncertainty}

A quantitative analysis of the aforementioned uncertainties requires an extension of the basic damage function. Here, we derive a comprehensive probabilistic framework for the unified damage function. The framework also forms the mathematical basis for the subsequent sensitivity analysis. 


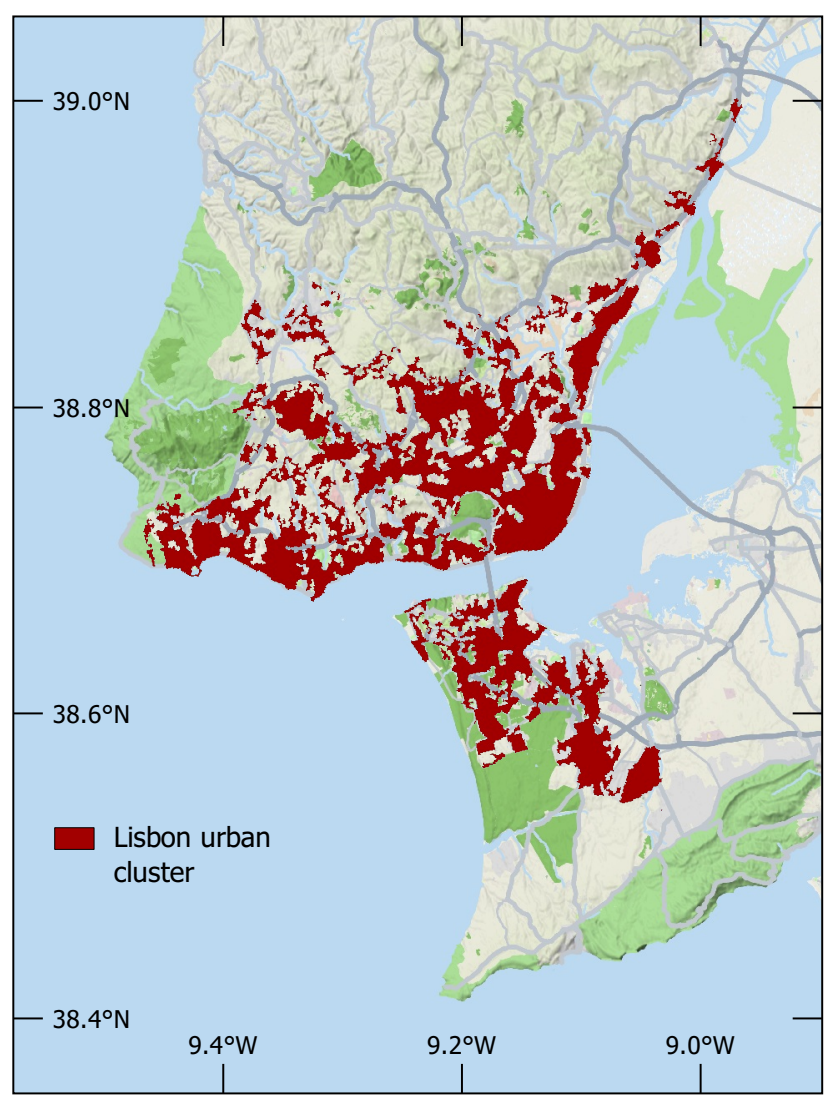

Figure 4. The Lisbon urban cluster supplied by B. Zhou (see Zhou et al., 2013). The red-shaded area represents continuous and discontinuous urban fabric as classified in the CORINE land cover data (Büttner et al., 2007).

We begin by defining random variables for each of the micro- and macroscale model variables. Microscale variables are the local hazard magnitude $\widetilde{X}$, the hazard threshold $\Lambda$, the threshold exceedance $E$, the inflicted relative damage $R$, and the relative asset weight $V$. The asset-weighted damage for a single object is described by $L$. Similarly, we define the macroscale random variables for the hazard magnitude and its measurement, $X$ and $\hat{X}$. The macroscale damage for the portfolio takes into account the different weights of the asset values and is described by $D$. In the following, the probability density distribution (PDF) of each random variable is denoted as $f_{(\cdot)}$.

The exceedance, $e=\tilde{x}-\lambda$, closely links the uncertainty in the local hazard magnitude with the uncertainty of the hazard threshold. The PDF of the random variable $E$ for the exceedance is hence given by the convolution of the PDFs of $X$ and $\Lambda$ as follows:

$f_{E \mid X=x}(e)=f_{\widetilde{X} \mid X=x}(\widetilde{x}) * f_{\Lambda}(-\lambda)$.

The distribution of the relative damage caused, $f_{R \mid E=e}(r)$, is conditional on the level of exceedance. The combination
Table 1. The number of inundated buildings within the Lisbon urban cluster at hypothetical flood levels between 0 and $10 \mathrm{~m}$.

\begin{tabular}{rrr}
\hline Flood level $(\mathrm{m})$ & \multicolumn{2}{c}{ Inundated buildings } \\
\cline { 2 - 3 } & Total & Increase $(\%)$ \\
\hline 0.0 & 0 & - \\
0.5 & 19 & - \\
1.0 & 28 & 47 \\
1.5 & 36 & 29 \\
2.0 & 43 & 19 \\
2.5 & 67 & 56 \\
3.0 & 107 & 60 \\
3.5 & 146 & 36 \\
4.0 & 210 & 44 \\
4.5 & 453 & 116 \\
5.0 & 670 & 48 \\
5.5 & 888 & 33 \\
6.0 & 1284 & 45 \\
6.5 & 1621 & 26 \\
7.0 & 1895 & 17 \\
7.5 & 2356 & 24 \\
8.0 & 2659 & 13 \\
8.5 & 3025 & 14 \\
9.0 & 3435 & 14 \\
9.5 & 3985 & 16 \\
10.0 & 4478 & 12 \\
\hline
\end{tabular}

with Eq. (9) yields an expression for the distribution of relative damage conditional on the hazard magnitude:

$f_{R \mid X=x}(r)=\int_{0}^{\infty} f_{R \mid E=e}(r) f_{E \mid X=x}(e) \mathrm{d} e$.

We define the asset-weighted damage as the product of relative damage and normalized asset value, $l=r v / n$. In the case that individual asset values are not known, a probabilistic asset weight $v$ is employed. Its $\mathrm{PDF}, f_{\mathrm{V}}(v)$, can be obtained by rescaling the PDF of absolute asset values such that the expected value equals 1 .

The PDF of $l$ is obtained by combining the PDF of asset weights with Eq. (10):

$f_{L \mid X=x}(l)=\int_{0}^{\infty} f_{R \mid X=x}(n l / v) f_{V}(v) \mathrm{d} v$.

Since the macroscale damage $d$ is the sum of the weighted microscale damages, its PDF is given by the convolution of the density functions for the asset-weighted damages of each of the $n$ portfolio items: 
Table 2. Parameterization of the probabilistic damage function for the estimation of damage from coastal flooding in Lisbon. The variables $\mu$ and $\sigma$ denote the mean and standard deviation respectively.

\begin{tabular}{lll}
\hline Component & Parameterization & References \\
\hline Portfolio composition & Frequency distribution for Lisbon & (this paper) see Table 1 \\
Microscale damage function & $g(z)=\frac{z}{z+1 \mathrm{~m}}$ & Hinkel et al. (2014) \\
Asset value & $\log \mathcal{N}(\mu=1, \sigma=0.5)$ & adapted from Ohnishi et al. (2011) \\
Damage level & $\log \mathcal{N}\left(\mu=g, \sigma_{g=0.5}=0.1\right)$ & (this paper) based on Lawrence (1988) \\
Threshold exceedance & $\mathcal{N}(\mu=x-\lambda, \sigma=0.2 \mathrm{~m})$ & Hallegatte et al. (2013) and EEA (2014) \\
Hazard magnitude & $\mathcal{N}(\mu=x, \sigma=0.1 \mathrm{~m})$ & Fortunato et al. (2014) \\
\hline
\end{tabular}

Table 3. Parameterization of the probabilistic damage function for the storm-damage simulation for a German building portfolio. The variables $\mu$ and $\sigma$ denote the mean and standard deviation respectively.

\begin{tabular}{lll}
\hline Component & Parameterization & References \\
\hline Portfolio composition & $\mathcal{N}\left(\mu=50.5 \mathrm{~m} \mathrm{~s}^{-1}, \sigma=7.8 \mathrm{~m} \mathrm{~s}^{-1}\right)$ & Heneka and Ruck (2008) \\
Microscale damage function & $g(z)=\left(\frac{z}{70 \mathrm{~m} \mathrm{~s}^{-1}}\right)^{2}$ & Heneka and Ruck (2008) \\
Asset value & $\log \mathcal{N}(\mu=1, \sigma=0.5)$ & adapted from Ohnishi et al. (2011) \\
Damage level & $\log \mathcal{N}\left(\mu=g(z), \sigma_{r=0.5}=0.1\right)$ & (this paper) based on Lawrence (1988) \\
Threshold exceedance & $\mathcal{N}\left(\mu=x-\lambda, \sigma=1 \mathrm{~m} \mathrm{~s}^{-1}\right)$ & (this paper) based on Mitsuta and Tsukamoto (1989) \\
Hazard magnitude & $\mathcal{N}\left(\mu=x, \sigma=1.5 \mathrm{~m} \mathrm{~s}^{-1}\right)$ & Prahl et al. (2012) and Hofherr and Kunz (2010) \\
\hline
\end{tabular}

$$
\begin{aligned}
D & =\sum_{i=1}^{n} L_{i} \\
f_{D \mid X=x}(d) & =f_{L_{1} \mid X} * f_{L_{2} \mid X} * \ldots * f_{L_{n} \mid X} .
\end{aligned}
$$

Finally, uncertainty in the true hazard magnitude $x$ (e.g. resulting from measurement or model output $\hat{x}$ ) is modelled via PDF $f_{X \mid \hat{X}=\hat{x}}(x)$. Using Eq. (12) it follows that

$$
f_{D \mid \hat{X}=\hat{x}}(d)=\int_{0}^{\infty} f_{D \mid X=x}(d) f_{X \mid \hat{X}=\hat{x}}(x) \mathrm{d} x .
$$

\section{Case studies for the sensitivity analysis}

Based on our taxonomy of uncertainties, we provide an exemplary parameterization of the unified damage function for two separate climate-related hazards: (i) coastal flooding in Lisbon, Portugal, and (ii) winter-storm damage for a German building portfolio comprised of 5000 individual buildings.

The Lisbon case exemplifies a bottom-up approach, where the individual hazard thresholds are known explicitly. Since coastal flooding is not bound by artificial administrative boundaries, we consider a cluster of continuous urban agglomeration in the Lisbon metropolitan area (Fig. 4). The cluster extent was kindly supplied by B. Zhou (see Zhou et al., 2013) and had been generated from 2006 CORINE land cover data (Büttner et al., 2007). It includes several connected suburbs along the shores of river Tejo and the north of the Setúbal peninsula.
The portfolio of flood-prone buildings within the cluster of Lisbon is based on statistical data provided by the Instituto Nacional de Estatística ${ }^{1}$, the national Portuguese statistics institute. Census data from 2007 on the number of buildings at the highest resolution available (Freguesia, i.e. urban quarters) were downscaled via the CORINE land cover classes for continuous and discontinuous urban fabric.

The number of buildings within each CORINE cell were assigned to elevation levels obtained from the EU-DEM ${ }^{2}$, a hybrid digital elevation model (DEM) based mainly on SRTM and ASTER GDEM data. A flood-fill algorithm (Poulter and Halpin, 2008) was employed to determine which DEM cells were affected at different flood levels, increasing in steps of $0.5 \mathrm{~m}$ up to a maximum of $10 \mathrm{~m}$. All employed data are publicly available. Table 1 shows the number of flooded buildings within the Lisbon urban cluster at flood levels up to $10 \mathrm{~m}$.

Microscale building damages in the Lisbon cluster are estimated with the damage function employed by Hinkel et al. (2014), described by a saturating power law $z /(z+1 \mathrm{~m})$. The function implies that relative damage increases proportional to the inundation level for $z \ll 1 \mathrm{~m}$ and saturates at 1 for large $z$.

A complementary top-down approach is pursued for the German building portfolio, with an implicit description of the hazard threshold by means of a probability density distribution. In the case of storm hazard, the determinants of the hazard threshold are less clear-cut than for flood damages.

\footnotetext{
${ }^{1}$ http://www.ine.pt

${ }^{2} \mathrm{http} / / /$ www.eea.europa.eu/data-and-maps/data/eu-dem
} 

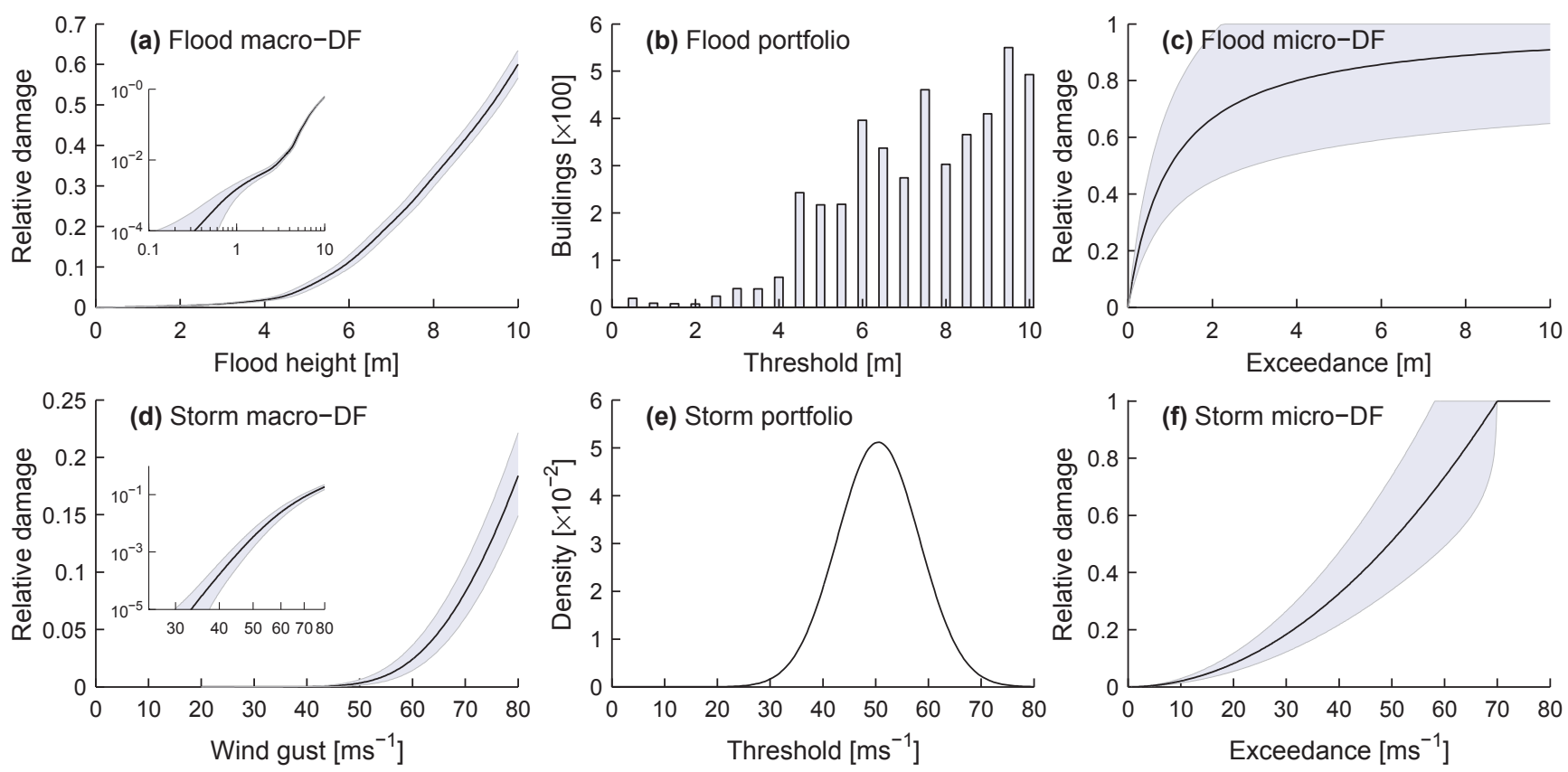

Figure 5. (a-c) show the damage function components for the case study of coastal flooding in Lisbon, Portugal. (d-f) demonstrate the methodology for storm damage within a building portfolio of 5000 individual buildings, based on the study by Heneka and Ruck (2008). The shaded areas around the damage functions indicate $95 \%$ confidence intervals. The insets in (a) and (d) show the macroscale damage function on a $\log -\log$ scale.

While they depend strongly on construction type and building age, a strong residual uncertainty remains. Heneka and Ruck (2008) argue for a simple statistical description of hazard thresholds via a normal distribution with mean $55 \mathrm{~m} \mathrm{~s}^{-1}$ and standard deviation $7.8 \mathrm{~m} \mathrm{~s}^{-1}$. Due to the lack of similar works, we adopt their parameterization to generate a generic portfolio of 5000 residential buildings.

The mean microscale damage caused by severe winds is often described as a power law with an upper bound representing complete destruction (Prahl et al., 2015). Again following Heneka and Ruck (2008), we apply a simple square power law.

Unlike the general features of the damage function, the nature of the uncertainties involved is typically not well understood and their quantification heavily relies on assumptions. Consequently, the required PDFs of the asset value, the microscale damage, the exceedance, and the hazard magnitude were estimated from literature, where available, and otherwise based on own considerations. Tables 2 and 3 provide a summary of the case study parameterization for each of the case studies, including the employed references. Due to the scarcity of information on uncertainty concerning microscale damage and the asset value, an identical parameterization was used for both case studies. Details on the estimation of uncertainties are given in Appendix A.

Figure $5 \mathrm{a}-\mathrm{c}$ and $\mathrm{d}-\mathrm{f}$ show the derived macroscale damage function, the portfolio composition, and the assumed microscale damage function for both cases respectively.

\section{Sensitivity analysis}

Going beyond the qualitative description of the involved uncertainties, this section focusses on their potential impact on damage estimates. From a non-linear damage function we expect potential interactions between different uncertainties that may vary with the hazard magnitude. Moreover, the analysis should take the different scales into account, as the macroscale damage is effectively an aggregation of microscale damages.

The influence of the various sources of uncertainty is assessed by performing a sensitivity analysis. Sensitivity analysis usually considers the effect of variation in one or more input variables on the dependent variable. For simple linear models, it may be sufficient to vary only one input variable at a time, since there is no interaction between different input variables. Non-linear models, in contrast, require a global sensitivity analysis, where simultaneous changes of all input variables are considered.

\subsection{Method}

We employ the VBSA, which estimates the contribution of each input variable to the total variance of the dependent variable (Saltelli et al., 2008). VBSA is a global sensitivity analysis and uses a Monte Carlo approach to sample from the probability distributions of the uncertain variables. 
The general algorithm of VBSA is summarized as follows. First, two $(s \times t)$ matrices $\mathbf{A}$ and $\mathbf{B}$ are defined, where each column vector represents one of the $t$ input variables that has been sampled $s$ times. Initially, the matrices are filled with uniformly distributed random values between 0 and 1 . Then, inverse cumulative distribution functions are used to convert the random vectors to the respective input variables of the model, i.e. the damage function. For each input variable with index $i$, a new matrix $\mathbf{C}_{(i)}$ is constructed, comprising all columns with index $j \neq i$ from $\mathbf{A}$ and the column $j=i$ from B.

The total-effect index is chosen as the main metric for sensitivity. It describes the share of output variance that is due to the direct and indirect effects of an uncertain variable. The direct effect (also called first-order effect) measures the lone contribution of varying a single variable, averaged over different realizations of the remaining variables. Indirect effects (higher-order effects) are due to interactions between two or more variables, e.g. a second-order effect may arise from the interaction between the threshold exceedance and the damage level.

The total-effects index $\mathrm{TE}_{i}$ of the damage function $\mathcal{F}(\cdot)$ is evaluated using the recommended Jansen estimator (Jansen, 1999; Saltelli et al., 2010):

$\mathrm{TE}_{i}=\frac{\frac{1}{2 s} \sum_{k=1}^{s}\left(\mathcal{F}(\mathbf{A})_{k}-\mathcal{F}\left(\mathbf{C}_{(i)}\right)_{k}\right)^{2}}{\sigma^{2}}$,

with

$$
\begin{aligned}
\sigma^{2} & =\frac{1}{2 s} \sum_{k=1}^{s}\left(\mathcal{F}(\mathbf{A})_{k}^{2}+\mathcal{F}(\mathbf{B})_{k}^{2}\right) \\
& -\left(\frac{1}{s} \sum_{k=1}^{s} \mathcal{F}(\mathbf{A})_{k}+\mathcal{F}(\mathbf{B})_{k}\right)^{2} .
\end{aligned}
$$

Note that in Eq. (15) we include both matrices $\mathbf{A}$ and $\mathbf{B}$ in order to obtain a closer estimate of the variance than by using matrix A alone.

The VBSA was applied on three distinct levels: (i) the microscale level related to a single item, (ii) the macroscale level limited to intrinsic uncertainty, and (iii) the macroscale level including extrinsic uncertainty. The sample size $s$ was set to 20000 . At level (i), $s$ random samples of the asset value $V$, the damage level $R$, and the exceedance $E$ were drawn from the probability distributions $f_{V}(v), f_{R \mid E=e}(r)$, and $f_{E \mid X=x}(e)$ respectively. At level (ii), the same procedure was applied, albeit for each of the items that sum up the portfolio. Finally, at level (iii), the hazard magnitude $X$ and the macroscale damage $D$ (including the effects of intrinsic uncertainties) were drawn from the distribution functions $f_{X \mid \hat{X}=\hat{x}}(x)$ and $f_{D \mid X=x}(d)$ respectively.

In order to evaluate the uncertainty of the sensitivity indices, the bootstrap method was used to obtain uncertainty intervals. Specifically, the $s$ random samples were resampled (i.e. selected randomly with replacement) 1000 times, and each time the sensitivity indices were recalculated. From the resulting distribution, the $95 \%$ uncertainty range was estimated.

\subsection{Results from the sensitivity analysis}

Figure 6 summarizes the VBSA results for the Lisbon case study. Figure 6a shows the total-effect index for the intrinsic uncertainties at the microscale level (i.e. concerning a single building). It can be seen that at low inundation levels uncertainty in the threshold exceedance (due to local hazard fluctuations and/or variation of the hazard threshold) dominates. However, at inundation levels beyond $1 \mathrm{~m}$ its relevance quickly diminishes and uncertainty in the building asset value dominates. While the effect of the damage-level uncertainty surpasses that of the uncertainty in the threshold exceedance at most inundation levels, it is generally outweighed by the uncertainty in asset value.

The overall behaviour seen for the microscale case also holds true for the accumulated building portfolio of Lisbon. Excluding extrinsic uncertainty, Fig. $6 \mathrm{~b}$ shows the sensitivity of the portfolio damage to intrinsic uncertainties. In contrast to the microscale case, the plot indicates a stronger impact of the uncertainty in the threshold exceedance. This behaviour arises from the fact that there are additional buildings affected as the flood level increases. Hence, the marked bump of the curve above $4 \mathrm{~m}$ flood height is explained by the strong increase of affected buildings at that elevation (cf. Table 1).

On the macroscale level, Fig. 6c shows the effect of the accumulated intrinsic uncertainties and the extrinsic uncertainty in the global hazard magnitude. The complex behaviour of the two curves can be decomposed into two main aspects. Firstly, the relative importance of intrinsic uncertainties decreases with rising flood levels. Secondly, the strong impact of intrinsic uncertainties around a flood level of $2 \mathrm{~m}$ results from the low fraction of newly affected buildings, as seen in Table 1. Higher fractions at $3 \mathrm{~m}$ and in particular beyond $4 \mathrm{~m}$ lead to an increased relevance of the uncertainty in hazard magnitude.

This behaviour can be explained as follows. For a fixed number of affected buildings, intrinsic uncertainty outpaces the uncertainty in hazard magnitude. However, an increase in affected buildings reduces the relative magnitude of intrinsic uncertainty due to diversification. This is not the case for the uncertainty in hazard magnitude, which acts as a bias for the entire portfolio.

The sum of the total-effect indices of each variable is equal to 1 only in the absence of higher-order effects. Sums larger than 1 are due to potential double counting, as higher-order effects are attributed to each of the interacting variables. It is clear from inspection that the results given in Fig. 6a-c indicate a minor role of higher-order effects. However, for completeness, we provide a detailed breakdown on first- and higher-order indices in the Supplement. 

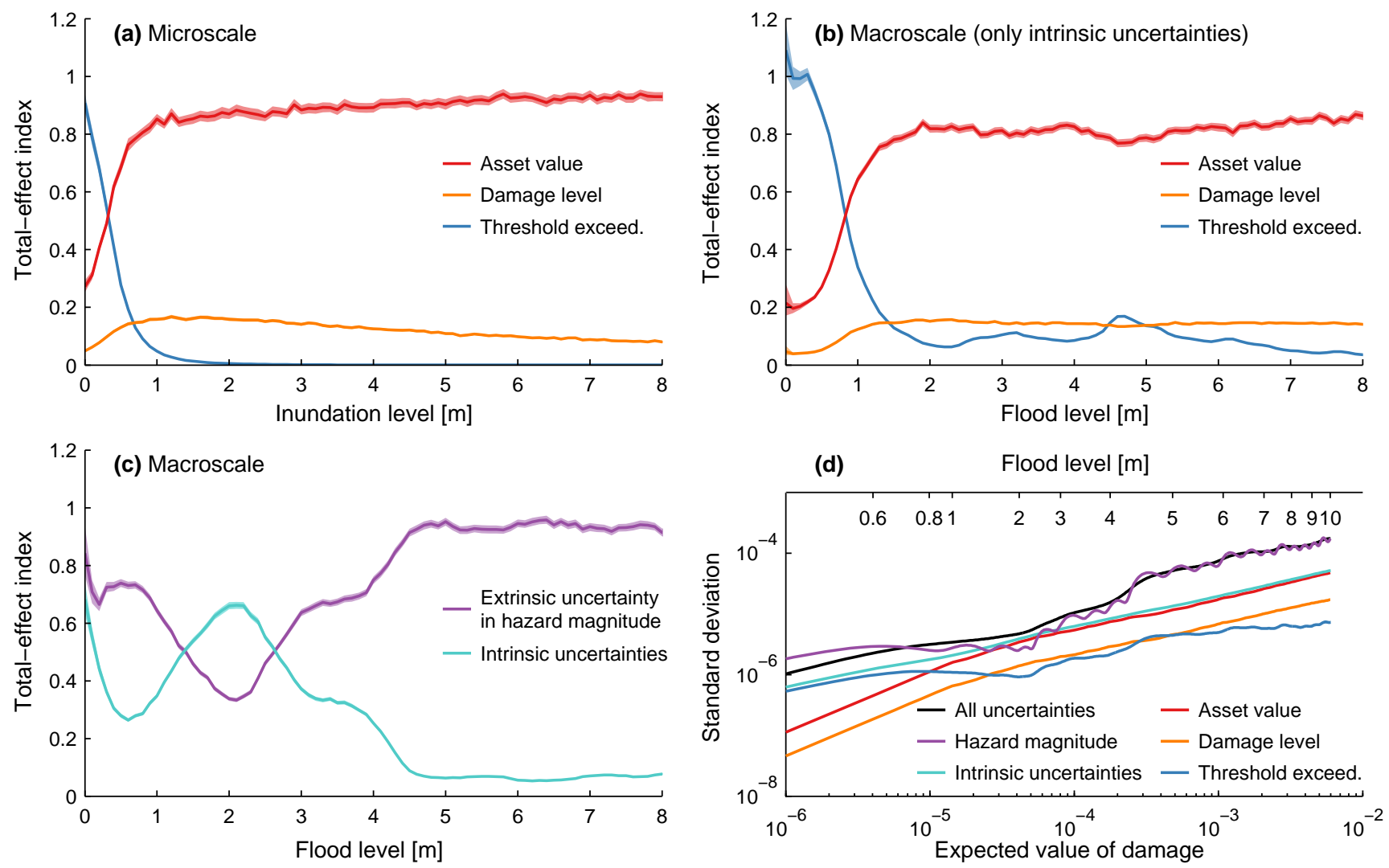

Figure 6. (a-c) show the results of variance-based sensitivity analysis (total-effect index) for the Lisbon case study at different scales. Shaded areas indicate boot-strapped confidence bands. For microscale damages, (a) shows the attributable effect of intrinsic uncertainty in asset value, damage, and threshold exceedance on the total variance. Similarly, (b) shows the effect of the intrinsic uncertainties on the variance of the aggregated portfolio. In (c), the portfolio-aggregated microscale uncertainties are weighed against the hazard uncertainty, i.e. error in estimated flood level. (d) shows the standard deviation against the expected value of flood damages on log-log scale. Each curve includes the uncertainty sources indicated by the legend.

In the absence of interaction, the relevance of the uncertainties is determined by their relative magnitude. In this regard, Fig. 6d shows the isolated effect of selected input variables on the standard deviation of damage estimates. The comparison with Figs. $6 \mathrm{~b}$ and $\mathrm{c}$ shows that the source of uncertainty exhibiting the largest standard deviation is also the dominating factor in the sensitivity analysis.

The sensitivity results obtained for the second case study - storm damage in a hypothetical German city - are similar to the Lisbon case. Figure 7a shows the relative contributions of the intrinsic uncertainties to the variance of the microscale damage. Despite the different shapes of the microscale damage function (cf. Figs. 5c and $\mathrm{f}$ ) there is a strong resemblance to Fig. 6a. A different behaviour is seen at an exceedance wind speed of $70 \mathrm{~ms}^{-1}$, where the microscale damage function reaches saturation. At this point, complete destruction has taken place, leaving only the uncertainty of the original asset value.

On the macroscale level, intrinsic uncertainties show a sensitivity that is similar to the microscale level. The curves shown in Fig. 7b are considerably smoother than those of the Lisbon case study. This underlines the conjecture that the irregularities in the Lisbon case study are due to the heterogeneous portfolio distribution. This aspect is also reflected in the relation between intrinsic uncertainties and the extrinsic uncertainty in the hazard magnitude in Fig. 7c. Here, the uncertainty in the hazard magnitude dominates for almost the entire range of gust speed. The narrowing at very low gust speeds is a result of the interdependence between the uncertainties in the exceedance and the hazard magnitude when the portfolio is barely affected. Finally, Fig. 7d complements the sensitivity results, showing the standard deviation of the potential storm damage against the expected value.

\section{Conclusions}

Based on damage assessments for coastal flood and storm hazards, a unified damage function was identified and embedded into a probabilistic framework for the consideration of uncertainty. 

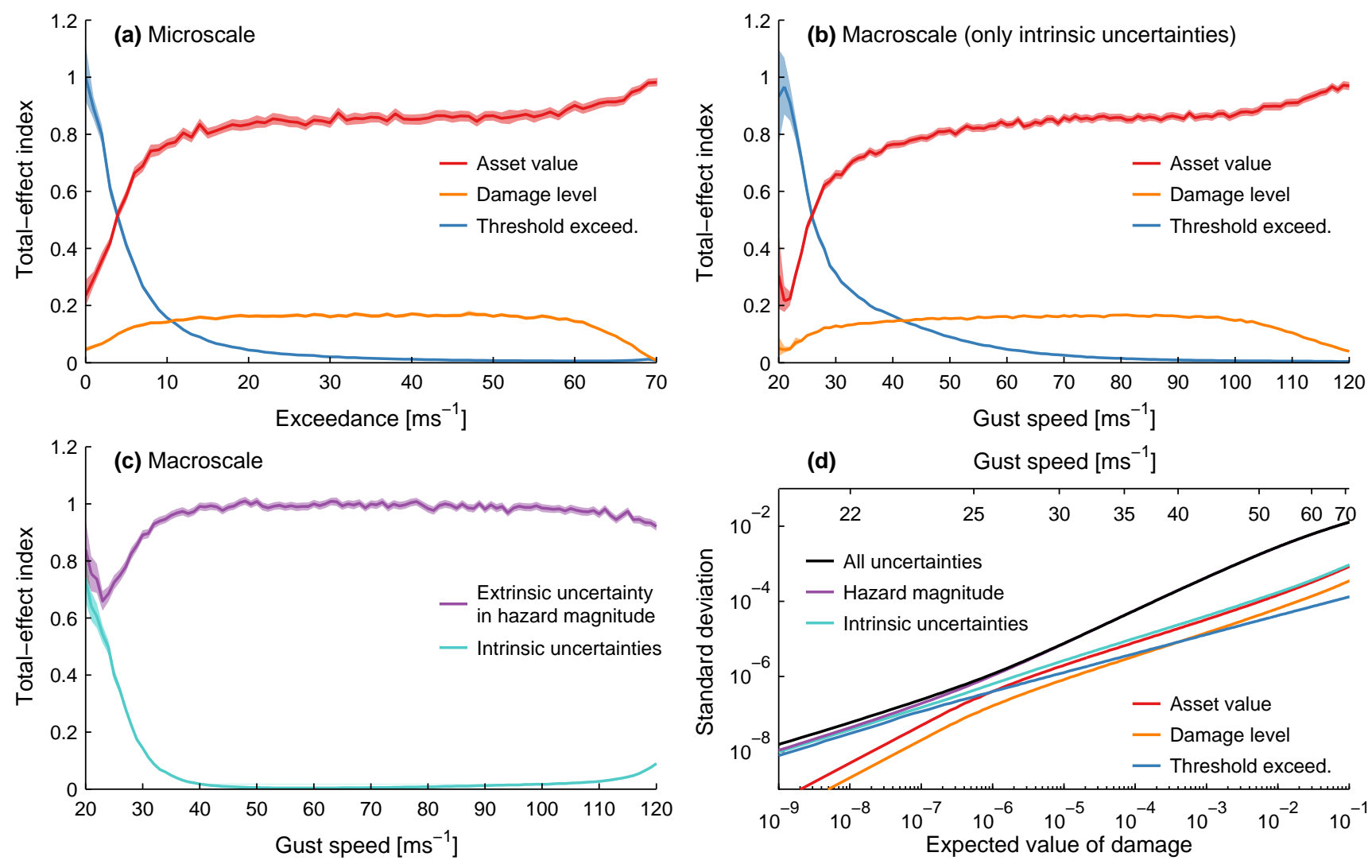

Figure 7. (a-c) show the results of variance-based sensitivity analysis (total-effect index) for the German storm-damage case study at different scales. Shaded areas indicate boot-strapped confidence bands. For microscale damages, (a) shows the attributable effect of intrinsic uncertainty in asset value, damage, and threshold exceedance on the total variance. Similarly, (b) shows the effect of the intrinsic uncertainties on the variance of the aggregated portfolio. In (c), the portfolio-aggregated microscale uncertainties are weighed against the hazard uncertainty, i.e. error in estimated flood level. (d) shows the increasing standard deviation against the expected value of damage estimates on a log-log scale. Each curve includes the uncertainty sources indicated by the legend.

While an exchange of information between the various hazard communities could potentially trigger methodological improvement (Merz et al., 2010), the approaches for assessing direct damage are typically hazard specific (Meyer et al., 2013). Hence, this study has investigated the analogies of the approaches for coastal flood, storm damage, and heatrelated mortality. The defining property of these approaches is the consideration of granular portfolios of exposed items (e.g. residential buildings) or people. In our view, the applicability of the unified approach extends to any hazard that affects such a granular portfolio. Furthermore, the unified approach represents a synthesis of synthetic bottom-up and empirical top-down damage evaluation. With its broad scope, it is seen as a potential building block towards a theory of damage functions.

Cross-hazard comparison of uncertainties within the unified approach has the potential to provide valuable insight on the nature and relevance of uncertainties along the causal chain. From a practitioner's point of view, determining the most relevant sources of uncertainty is arguably more im- portant than quantifying each potential uncertainty source. Serving this purpose, valuable insight could be gained from a variance-based sensitivity analysis of the unified damage function. The analysis goes beyond similar studies (e.g. Egorova et al., 2008; de Moel and Aerts, 2011) by considering uncertainty on both the microscale and macroscale levels, as well as at different hazard magnitude. Investigating both the case of coastal flooding for the city of Lisbon and the case of storm damage in a German town, a set of general conclusions could be drawn.

On a general level, extrinsic and intrinsic sources of uncertainty were distinguished. Extrinsic sources manifest as a random bias for the entire portfolio (e.g. hazard magnitude), while intrinsic uncertainties arise locally and affect individual portfolio items (w.r.t. asset value, damage level, and threshold exceedance).

As demonstrated by both case studies, extrinsic uncertainty can play a crucial role as the dominant source of uncertainty. In contrast to the intrinsic uncertainties, whose aggregated effect (i.e. in terms of the standard deviation of 
the macroscale damage) increases sub-linearly with portfolio size due to diversification, the effect of extrinsic uncertainty is directly proportional to portfolio size. Hence, given a sufficiently large portfolio and uncertainty in the hazard magnitude, intrinsic uncertainty sources may be negligible for damage assessment. This is of particular importance in climate science, where practitioners often deal with ensemble simulations exhibiting large model spreads. It is also relevant for natural hazard research, where extreme value theory often implies broad confidence intervals for extreme events.

An example where this result allows for additional insight is the work of Heneka and Ruck (2008). In their damage assessment, uncertainty was attributed to a random bias on the threshold distribution for each post-code area. However, the assumed bias is equivalent to an uncertainty in the hazard magnitude, i.e. error from physical modelling. Such uncertainty in gust estimation is not only more intuitive than a threshold bias but also consistent with the validation results of the employed atmospheric model (Hofherr and Kunz, 2010).

Considering the relevance of intrinsic uncertainty sources, our results show that the composition of uncertainty within the microscale damage function largely determines the role of intrinsic uncertainties at the portfolio level.

Amongst the intrinsic uncertainties, the uncertainty due to local threshold exceedance (being a combination of local hazard fluctuations and local variations in hazard threshold) is only significant for low hazard magnitudes. This magnitude range may not be relevant in certain cases, e.g. focussing on high-end scenarios or including protective measures such as sea walls. The case studies also show the extent to which variability in asset values can dominate intrinsic uncertainty. While that uncertainty could be reduced if spatially resolved data were available, this is typically not the case for datascarce regions within developing countries, which are also more severely affected by natural disasters (IPCC, 2012).

Despite the different microscale damage functions used, both case studies show a similar sensitivity to uncertainties. This indicates that the validity of our conclusions on uncertainty reaches beyond the considered hazards. Moreover, the effect of different microscale damage functions (of the same one-parameter family) could be simulated by a re-scaling. For the sensitivity results, for example, a more shallow microscale damage function would result in a stretch along the hazard axis, while preserving overall behaviour.
The effect of large-scale protection measures, e.g. sea walls, was not considered in this study for two reasons. Firstly, such measures are specific to flood hazards and have no counterpart for other hazards, such as wind storms. Secondly, sea walls modify the incident hazard by interrupting events below the design protection level and are hence not an immediate component of damage estimation. However, it is known that the probability of protection failure, e.g. crevasses, represents a major source of uncertainty for damage assessment (de Moel et al., 2012).

In practice, there are some limitations to the unified damage function that arise from the simplicity of the approach. At increased cost and effort of data acquisition, more specialized approaches could provide superior damage estimates (e.g. Kreibich et al., 2010; Pita et al., 2013). However, the strengths of the discussed approach are in its versatility and the ability to provide valuable insight for applications where detailed data for calibration and validation are missing. The latter aspect is highlighted by our general conclusions on uncertainties. Given the evident lack of reliable information on uncertainty, as encountered for the parameterizations of our case studies, the results may guide further investigation.

Addressing the need for comprehensive approaches for risk analyses and management, we have shown that certain damage functions for coastal floods and windstorms are two facets of a unified damage function. Further, it was indicated how this unified approach could be extended to the estimation of heat-wave fatalities.

With its wide applicability to the assessment of both loss and fatalities, the unified damage function has the potential to facilitate knowledge transfer between climate-related hazards and to narrow the gap for a multi-hazard damage assessment. Moving towards this goal, the interdependence and cascading effects of climate-related hazards become of wider concern. For further research, we hence propose the extension of the unified approach to include non-stationary hazard thresholds. 


\section{Appendix A: Uncertainty parameterization}

\section{A1 Lisbon case study for coastal flooding}

\section{A1.1 Hazard magnitude uncertainty}

For our case study region, the Portuguese coast and in particular Cascais, Fortunato et al. (2014) estimate a tidal uncertainty of $5 \mathrm{~cm}$ and an uncertainty of approximately $10 \mathrm{~cm}$ for extreme water levels calculated by a dedicated circulation model. Based on this result and due to the lack of information on the distribution of uncertainty, we make the assumption of a normally distributed error in overall flood level with a standard deviation of $10 \mathrm{~cm}$. If ensemble predictions of surge levels were available, the ensemble spread (standard deviation) could serve as a indicator for the forecast error (Flowerdew et al., 2009, 2010).

\section{A1.2 Threshold exceedance uncertainty}

Modelling flood damages, exceedance uncertainty is mostly driven by errors related to the elevation model used. For Portugal, statistical validation of the EU-DEM against ICESat measurements (EEA, 2014) indicates a mean error $>0.5 \mathrm{~m}$ and an average standard deviation of approximately $2 \mathrm{~m}$. However, errors in flood-prone lowlands are expected to be strongly spatially correlated and to exhibit less local fluctuations (Hallegatte et al., 2013). In the lack of a detailed DEM validation for Lisbon, we assume a modest normally distributed pixel error with a standard deviation of $0.2 \mathrm{~m}$.

\section{A1.3 Damage level uncertainty}

Actuarial practice suggests that the log-normal distribution may serve as a first approximation to the broadly skewed damage claim distributions (Lawrence, 1988). By applying a constant scale factor, the log-normal distribution represents a multiplicative error term that is proportional to the average damage caused. Defining the microscale damage curve as the mean of the log-normal distribution, we set the scale factor such that the standard deviation $\sigma=0.1$ at a relative damage $d=0.5$, implying a standard deviation of approximately $20 \%$ for $d \ll 1$. The upper tail of the log-normal damage distribution is truncated at $d=1$, which represents complete destruction and loss.

\section{A1.4 Asset value variation}

Regarding storm or flood damages to individual buildings, the built-up values can be approximated by the distribution in house prices. For the case of Tokyo, Ohnishi et al. (2011) show that house prices generally follow a log-normal distribution, with price bubbles affecting mainly the tails of the distribution. While comparable studies are not available for the European region, one may assume that relative house prices follow a similar distributional shape and width. On relative terms, the results by Ohnishi et al. (2011) translate to a log-normal distribution normalized to an average value $\mu=1$ and with a standard deviation $\sigma=0.5$.

\section{A2 Storm damages in a German building portfolio}

\section{A2.1 Hazard magnitude uncertainty}

For maximum wind gusts, which are required for the assessment of storm damages, Prahl et al. (2012) report a strong variation between measurements at nearby sites and estimate that $75 \%$ of measurements fall within the range of $\pm 1.5 \mathrm{~m} \mathrm{~s}^{-1}$. Reports show an even stronger modelling uncertainty when comparing gust estimates from a mesoscale atmospheric model from a mesoscale atmospheric model with measured gusts (e.g. Ágústsson and Ólafsson, 2009; Hofherr and Kunz, 2010). In our calculations, we hence assume wind gust uncertainty to follow normal distribution with a standard deviation $\sigma=1.5 \mathrm{~m} \mathrm{~s}^{-1}$.

\section{A2.2 Threshold exceedance uncertainty}

Wind gusts exhibit a strong spatial variability at short ranges. This aspect is demonstrated, inter alia, by the fact that the $3 \mathrm{~s}$ gust factor (relating extreme wind gust to mean wind speed) drops by more than $20 \%$ if spatial averaging is applied for short distances less than $1 \mathrm{~km}$ (Mitsuta and Tsukamoto, 1989). While there is no indication in the scientific literature on the uncertainty in storm hazard threshold, the macroscale uncertainty in storm gust speed poses an upper bound for the local gust variability. In line with macroscale gust speed uncertainty, we assume a normally distributed local variability, albeit with a reduced standard deviation of $1 \mathrm{~m} \mathrm{~s}^{-1}$.

\section{A2.3 Damage level uncertainty and variation in asset values}

In the lack of local empirical studies for the uncertainty in damage levels or the variation in asset values, we employ an identical parameterization for both the coastal flooding and the storm hazard case studies. The parameterization for the damage level uncertainty and the variation in asset values is described in Sect. A1. 


\section{The Supplement related to this article is available online at doi:10.5194/nhess-16-1189-2016-supplement.}

Acknowledgements. We appreciate valuable discussions with U. Ulbrich and L. Krummenauer. This work was produced using Copernicus data and information funded by the European Union EU-DEM layers. This work was supported by the European Community's Seventh Framework Programme under grant agreement no. 308497 (Project RAMSES).

Edited by: H. Kreibich

Reviewed by: four anonymous referees

\section{References}

Ágústsson, H. and Ólafsson, H.: Forecasting wind gusts in complex terrain, Meteorol. Atmos. Phys., 103, 173-185, doi:10.1007/s00703-008-0347-y, 2009.

Bedford, T. and Cooke, R.: Probabilistic Risk Analysis - Foundations and Methods, Cambridge University Press, Cambridge, UK, 33 pp., 2001.

Boettle, M., Kropp, J. P., Reiber, L., Roithmeier, O., Rybski, D., and Walther, C.: About the influence of elevation model quality and small-scale damage functions on flood damage estimation, Nat. Hazards Earth Syst. Sci., 11, 3327-3334, doi:10.5194/nhess-113327-2011, 2011.

Boettle, M., Rybski, D., and Kropp, J. P.: Quantifying the effect of sea level rise and flood defence - a point process perspective on coastal flood damage, Nat. Hazards Earth Syst. Sci., 16, 559576, doi:10.5194/nhess-16-559-2016, 2016.

Büttner, G., Soukup, T., and Sousa, A.: CLC2006 technical guidelines, Tech. Rep. 17, European Environmental Agency, Copenhagen, Denmark, 2007.

Coles, S. and Tawn, J.: Bayesian modelling of extreme surges on the UK east coast, Philos. T. R. Soc. A, 363, 1387-1406, doi:10.1098/rsta.2005.1574, 2005.

de Moel, H. and Aerts, J. C. J. H.: Effect of uncertainty in land use, damage models and inundation depth on flood damage estimates, Nat. Hazards, 58, 407-425, doi:10.1007/s11069-0109675-6, 2011.

de Moel, H., Asselman, N. E. M., and Aerts, J. C. J. H.: Uncertainty and sensitivity analysis of coastal flood damage estimates in the west of the Netherlands, Nat. Hazards Earth Syst. Sci., 12, 10451058, doi:10.5194/nhess-12-1045-2012, 2012.

Egorova, R., van Noortwijk, J. M., and Holterman, S. R.: Uncertainty in flood damage estimation, Int. J. Riv. Bas. Manage., 6, 139-148, doi:10.1080/15715124.2008.9635343, 2008.

EEA: EU-DEM Statistical Validation, prepared for the European Environmen Agency (EEA) by DHI GRAS, Copenhagen, Denmark, available at: http: //ec.europa.eu/eurostat/documents/4311134/4350046/ Report-EU-DEM-statistical-validation-August2014.pdf （last access: 15 May 2015), 2014.

Flowerdew, J., Horsburgh, K., and Mylne, K.: Ensemble forecasting of storm surges, Mar. Geod., 32, 91-99, doi:10.1080/01490410902869151, 2009.
Flowerdew, J., Horsburgh, K., Wilson, C., and Mylne, K.: Development and evaluation of an ensemble forecasting system for coastal storm surges, Q. J. Roy. Meteor. Soc., 136, 1444-1456, doi:10.1002/qj.648, 2010.

Fortunato, A., Li, K., Bertin, X., and Rodrigues, M.: Determination of extreme sea levels along the Portuguese coast, in: Actas das 3.as Jornadas de Engenharia Hidrográfica, Instituto Hidrográfico, Lisbon, Portugal, 151-154, 2014.

Gasparrini, A., Guo, Y., Hashizume, M., Lavigne, E., Zanobetti, A., Schwartz, J., Tobias, A., Tong, S., Rocklöv, J., Forsberg, B., Leone, M., De Sario, M., Bell, M. L., Guo, Y.-L. L., Wu, C.f., Kan, H., Yi, S.-M., de Sousa Zanotti Stagliorio Coelho, M., Saldiva, P. H. N., Honda, Y., Kim, H., and Armstrong, B.: Mortality risk attributable to high and low ambient temperature: a multicountry observational study, Lancet, 386, 369-375, doi:10.1016/S0140-6736(14)62114-0, 2015.

Golnaraghi, M., Etienne, C., Sapir, D. G., and Below, R.: Atlas of Mortality and Economic Losses from Weather, Climate and Water Extremes (1970-2012), WMO-No. 1123, World Meteorological Organization, Geneva, Switzerland, 2014.

Hallegatte, S., Green, C., Nicholls, R. J., and Corfee-Morlot, J.: Future flood losses in major coastal cities, Nature Clim. Change, 3, 802-806, doi:10.1038/nclimate1979, 2013.

Hammond, M., Chen, A., Djordjević, S., Butler, D., and Mark, O.: Urban flood impact assessment: a state-of-the-art review, Urban Water J., 12, 14-29, doi:10.1080/1573062X.2013.857421, 2015.

Heneka, P. and Ruck, B.: A damage model for the assessment of storm damage to buildings, Eng. Struct., 30, 3603-3609, doi:10.1016/j.engstruct.2008.06.005, 2008.

Hinkel, J., Lincke, D., Vafeidis, A. T., Perrette, M., Nicholls, R. J., Tol, R. S. J., Marzeion, B., Fettweis, X., Ionescu, C., and Levermann, A.: Coastal flood damage and adaptation costs under 21st century sea-level rise, P. Natl. Acad. Sci. USA, 111, 3292-3297, doi:10.1073/pnas.1222469111, 2014.

Hofherr, T. and Kunz, M.: Extreme wind climatology of winter storms in Germany, Clim. Res., 41, 105-123, doi:10.3354/cr00844, 2010.

IPCC: Managing the Risks of Extreme Events and Disasters to Advance Climate Change Adaptation: a Special Report of Working Groups I and II of the Intergovernmental Panel on Climate Change, Cambridge University Press, Cambridge, UK, New York, NY, USA, 2012.

Jansen, M. J.: Analysis of variance designs for model output, Comput. Phys. Commun., 117, 35-43, doi:10.1016/S00104655(98)00154-4, 1999.

Kreibich, H., Seifert, I., Merz, B., and Thieken, A. H.: Development of FLEMOcs - a new model for the estimation of flood losses in the commercial sector, Hydrolog. Sci. J., 55, 1302 1314, doi:10.1080/02626667.2010.529815, 2010.

Kreibich, H., Bubeck, P., Kunz, M., Mahlke, H., Parolai, S., Khazai, B., Daniell, J., Lakes, T., and Schröter, K.: A review of multiple natural hazards and risks in Germany, Nat. Hazards, 74, 2279-2304, doi:10.1007/s11069-014-1265-6, 2014.

Lawrence, R. J.: Applications in economics and business, in: Lognormal Distributions: Theory and Applications, edited by: Crow, E. L. and Shimizu, K., Marcel Dekker, New York, 229266, 1988.

Leone, M., D'Ippoliti, D., De Sario, M., Analitis, A., Menne, B., Katsouyanni, K., de' Donato, F., Basagana, X., Salah, A., 
Casimiro, E., Dortbudak, Z., Iniguez, C., Peretz, C., Wolf, T., and Michelozzi, P.: A time series study on the effects of heat on mortality and evaluation of heterogeneity into European and EasternSouthern Mediterranean cities: results of EU CIRCE project, Environ. Health-UK, 12, doi:10.1186/1476-069X-12-55, 2013.

Merz, B., Kreibich, H., Thieken, A., and Schmidtke, R.: Estimation uncertainty of direct monetary flood damage to buildings, Nat. Hazards Earth Syst. Sci., 4, 153-163, doi:10.5194/nhess-4-1532004, 2004.

Merz, B. and Thieken, A.: Flood risk curves and uncertainty bounds, Nat. Hazards, 51, 437-458, doi:10.1007/s11069-0099452-6, 2009.

Merz, B., Kreibich, H., Schwarze, R., and Thieken, A.: Review article "Assessment of economic flood damage", Nat. Hazards Earth Syst. Sci., 10, 1697-1724, doi:10.5194/nhess-10-16972010, 2010.

Meyer, V., Becker, N., Markantonis, V., Schwarze, R., van den Bergh, J. C. J. M., Bouwer, L. M., Bubeck, P., Ciavola, P., Genovese, E., Green, C., Hallegatte, S., Kreibich, H., Lequeux, Q., Logar, I., Papyrakis, E., Pfurtscheller, C., Poussin, J., Przyluski, V., Thieken, A. H., and Viavattene, C.: Review article: Assessing the costs of natural hazards - state of the art and knowledge gaps, Nat. Hazards Earth Syst. Sci., 13, 1351-1373, doi:10.5194/nhess-13-1351-2013, 2013.

Mitsuta, Y. and Tsukamoto, O.: Studies on spatial structure of wind gust, J. Appl. Meteorol., 28, 1155-1160, doi:10.1175/15200450(1989)028<1155:SOSSOW >2.0.CO;2, 1989.

Munich Re: Topics Geo - Natural Catastrophes 2012 - Analyses, Assessments, Positions, Münchener RückversicherungsGesellschaft, Munich, Germany, 54-55, 2013.

Ohnishi, T., Mizuno, T., Shimizu, C., and Watanabe, T.: The Evolution of House Price Distribution, RIETI Discussion Paper Series 11-E-019, Research Institute of Economy, Trade and Industry, Tokyo, Japan, 2011.

Pita, G. L., Pinelli, J.-P., Gurley, K. R., and Hamid, S.: Hurricane vulnerability modeling: Development and future trends, J. Wind Eng. Ind. Aerodyn., 114, 96-105, doi:10.1016/j.jweia.2012.12.004, 2013.
Poulter, B. and Halpin, P. N.: Raster modelling of coastal flooding from sea-level rise, Int. J. Geogr. Inf. Sci., 22, 167-182, doi:10.1080/13658810701371858, 2008.

Prahl, B. F., Rybski, D., Kropp, J. P., Burghoff, O., and Held, H.: Applying stochastic small-scale damage functions to German winter storms, Geophys. Res. Lett., 39, L06806, doi:10.1029/2012GL050961, 2012.

Prahl, B. F., Rybski, D., Burghoff, O., and Kropp, J. P.: Comparison of storm damage functions and their performance, Nat. Hazards Earth Syst. Sci., 15, 769-788, doi:10.5194/nhess-15-769-2015, 2015.

Saltelli, A., Ratto, M., Andres, T., Campolongo, F., Cariboni, J., Gatelli, D., Saisana, M., and Tarantola, S.: Global Sensitivity Analysis, The Primer, John Wiley \& Sons, West Sussex, UK, 155-182, 2008.

Saltelli, A., Annoni, P., Azzini, I., Campolongo, F., Ratto, M., and Tarantola, S.: Variance based sensitivity analysis of model output, Design and estimator for the total sensitivity index, Comput. Phys. Commun., 181, 259-270, doi:10.1016/j.cpc.2009.09.018, 2010.

Stafoggia, M., Forastiere, F., Agostini, D., Biggeri, A., Bisanti, L., Cadum, E., Caranci, N., de'Donato, F., De Lisio, S., De Maria, M., Michelozzi, P., Miglio, R., Pandolfi, P., Picciotto, S., Rognoni, M., Russo, A., Scarnato, C., and Perucci, C. A.: Vulnerability to heat-related mortality: a multicity, population-based, case-crossover analysis, Epidemiology, 17, 315-323, doi:10.1097/01.ede.0000208477.36665.34, 2006.

Walker, G. R.: Modelling the vulnerability of buildings to wind - a review, Can. J. Civ. Eng., 38, 1031-1039, doi:10.1139/111-047, 2011.

Zhou, B., Rybski, D., and Kropp, J. P.: On the statistics of urban heat island intensity, Geophys. Res. Lett., 40, 5486-5491, doi:10.1002/2013GL057320, 2013. 